\title{
Dos Corpos em Redeàs Máquinas em Rede: Reestruturação do Trabalho Bancário e Constituição do Sujeito
}

\author{
Carmen Lígia Iochins Grisci
}

\begin{abstract}
Resumo
O presente artigo resulta de uma pesquisa que trata da inter-relação trabalho, tempo e subjetividade, focando-se na reestruturação do trabalho bancário e constituição do sujeito. Trata-se de um estudo de caso realizado em instituição bancária; os dados foram coletados em fontes documentais e iconográficas, discussões com grupos focais e entrevistas individuais semidirigidas. A análise dos dados seguiu orientações de Thompson para a Metodologia da Hermenêutica de Profundidade e discute dois eixos centrais: historicidade e modos organizacionais, e reestruturação do trabalho e constituição do sujeito. Os resultados da pesquisa apontam para a constituição de um sujeito que, em plena reestruturação do trabalho bancário, se vê desalojado das certezas em face da intensificação da pressão à aceitação das mudanças incessantes, regidas por modos de apresentação como inevitabilidade, instantaneidade e intensidade que vêem a acarretar supersolicitação e sofrimento psíquico.
\end{abstract}

Palavras-chaves: trabalho; mudança; tempo; subjetividade.

\section{Abstract}

This paper results from research dealing with the relationship between work, time and subjectivity, with a focus on the restructuring of banking work and subject constitution. It is a case study carried out in a bank, with data collection taking place through iconographic and documentary sources, focus group analyses and semi-directed individual interviews. Data analysis was in accordance with Thompson's guidelines for the Methodology of Hermeneutics and Depth. Two major areas are under discussion: history and organizational modes, and the restructuring of work and subject constitution. Research results indicate the constitution of a subject who finds himself or herself without many certainties in the face of intensified pressure to accepting ceaseless changes. These changes are the result of inevitability, instantaneousness and intensity which cause physic suffering and demands in excess.

Key words: work; change; time; subjectivity. 


\section{INTRODUÇÃO}

Trabalho, tempo e subjetividade são categorias de análise que fundamentam a discussão proposta neste artigo acerca da reestruturação do trabalho bancário e constituição do sujeito. Tal discussão é tecida desde uma perspectiva teórica que pressupõe que trabalho e tempo atuam entrelaçados, agindo um sobre o outro, em termos de produção de subjetividade.

Tratando o trabalho como uma categoria de análise que permite significativas e recorrentes abordagens, propõe-se o recorte referente a um modo de trabalho capitalista que, em sua constante busca por acumulação de riqueza, apresenta visíveis e inegáveis transformações. Tais transformações unem-se sobremaneira à questão do tempo. Sob esse prisma, interessa, especificamente, enfocar aspectos que venham a fundamentar as relações entre modos de trabalhar e de subjetivação, uma vez que se pressupõem modos de trabalhar como dispositivos de construção da maneira de ser e de viver. O trabalho é assumido, então, a exemplo de outras áreas do conhecimento, não "como objeto da razão instrumental aplicada, mas como objeto de análise da situação do homem no fazer-se através do tempo" (Dal Rosso, 1996, p. 64).

Adianta-se, antes de tudo, que o tempo é uma categoria difícil, até porque, diferentemente do espaço, o tempo não se vê, se experimenta. Busca-se, então, tomá-lo enquanto possibilidade de construção de modos de viver, em suas formas contemporâneas: atravessado pela velocidade, como também imbricado nas transformações emergentes do mundo social e do trabalho. Para tanto, faz-se necessário transpor os limites identificatórios de uma ou outra disciplina do conhecimento e assumir a inexistência de concepção filosófica homogênea a respeito do que seja o tempo, engendrando-se aí não a busca de uma essência do tempo, mas o rastreamento de seus operadores, idéias, imagens e experiências a ele relacionadas.

A noção de subjetividade que se apresenta diz dos estilos de vida ou modos de existência ou modos de subjetivação que se geram no cerne do trabalho contemporâneo. Tomada como coletiva, social e histórica, a subjetividade varia conforme as determinações sociais, econômicas e tecnológicas de cada época. Varia, portanto, de acordo com as reestruturações que sofre o mundo do trabalho.

Embora a reestruturação não seja exclusividade do setor bancário, este setor, inscrito no atual movimento de reestruturação do trabalho, indica a criação de 
nova ordem do processo do trabalho bancário relacionada às inovações tecnológicas voltadas ao aumento da produtividade humana e à maximização dos recursos disponíveis. O trabalho bancário evidencia transformações no processo de produção que dizem respeito à oferta de produtos cada vez mais diversificados e destinados a atender às especificidades da clientela; à redução de tempos vazios possibilitada pela multifuncionalidade que passa a caracterizar seus trabalhadores, o que lhes atribui a condição de trabalhadores disponíveis para a realização de quaisquer tarefas, ou de trabalhadores que respondem a toda e qualquer demanda que se apresente.

Esse é o cenário que, no plano da organização do trabalho e da produção, imprime mudanças indicativas de um reordenamento dos processos produtivos, a partir de base tecnológica bem delimitada em seus perfis e em suas tendências de localização e ocupação, para outra, bem menos definida e mais flexível, em que as categorias tempo e subjetividade alcançam nova compreensão.

Desse modo, o problema de pesquisa que se apresenta procura relacionar três problemáticas centrais. A primeira é a categoria trabalho que, segundo alguns autores, reivindica um alargamento de seu conceito, devido tanto à inclusão de novos sujeitos em cena, quanto à exclusão de outros, isto é, trabalho como universo de significados, cujas transformações no tempo e na história trazem implicações nos modos de ser e de viver.

A segunda tem que ver com tempos novos, tempos a indicar coexistências, a enaltecer o aqui e agora, tempos atravessados por velocidades extraordinárias que desvalorizam passado, presente e futuro e, conseqüentemente, tornam obsoletas as trajetórias dos sujeitos; tempos que, sem dúvida, necessitam novas compreensões.

Finalmente, a terceira é a problemática da subjetividade, entendida como diferentes expressões de como os trabalhadores são afetados por um mundo que se mostra em constante mutação.

O problema de pesquisa concentra-se, então, na seguinte questão: como trabalho e tempo, inter-relacionados, repercutem na subjetividade de trabalhadores, especificamente os que exercem as suas atividades no setor de prestação de serviços bancários? 


\section{ReVisão da Literatura}

No mundo do trabalho contemporâneo, particularmente, observa-se que as mudanças decorrentes dos processos de virtualização propiciados pela informática, da comunicação instantânea e globalizada, da rapidez dos fluxos e das empresas virtuais, indicam a experimentação de novas temporalidades, que são da ordem de tecnologias que possibilitam viver novas dimensões independentes de sua concretude no espaço (Lévy, 1996a; Virilio, 1996a).

O diagnóstico que Lévy (1996b) e Virilio (1996b) fazem coincide quanto à ocorrência e à intensidade das mudanças contemporâneas. A respeito do que advém de tais mudanças, entretanto, tecem formulações diferenciadas, explicitando contrapontos que, no contexto bancário em tempos de reestruturação, podem vir a ser tomados desde a complexidade que envolve a lógica do e/e (lógica da inclusão), em detrimento da lógica do ou/ou (lógica da exclusão). Tal posicionamento faz eco ao pensamento de Guattari (1997, p. 15), quanto às transformações tecnológicas, no sentido de que elas "obrigam a evitar qualquer ilusão progressista ou qualquer visão sistematicamente pessimista”.

O que comumente se observa é que às inovações tecnológicas agregam-se discursos organizacionais que se pretendem bem articulados e politicamente corretos, indicando formas ditas diferenciadas de gestão, como o neotaylorismo, o tecnoburocrático, o baseado na excelência e o participativo, entre outros (Chanlat, 1996). Embora essas formas de referir repercutam direta e diferentemente na construção dos sujeitos do trabalho, é notório que não minimizam, nos sujeitos, os sentimentos de constante falta, despreparo e insegurança, ou seja, de constante "estado de emergência”, no dizer de Virilio (1996b), em face das possibilidades de exclusão do mercado de trabalho em transformação, no utilizar-se justamente das ditas formas de gestão politicamente corretas.

Nesse sentido, Itani (1997) acentua o fato de que, desde a década de 70 do século anterior, há interesse acerca das conseqüências das inovações tecnológicas. O interesse, no entanto, converge para os efeitos mais visíveis de tais inovações, sendo que a busca pelo conhecimento do que representam para os trabalhadores manteve-se marginalizada na atual "desordem do trabalho" (Mattoso, 1995). Isso indica que, embora não mais apresentados como aqueles trabalhadores massificados que o fordismo cunhou, os trabalhadores de hoje encontram-se em nova ordem de massificação. A ordem da massa dos excluídos que aumenta vertiginosamente as filas do desemprego devido a um mundo do trabalho que não mais necessita de sua força para se movimentar (Forrester, 1997). 
Desde as perspectivas apresentadas até então, têm-se hoje novas possibilidades de se conectar trabalho e tempo, já que a "urgência do tempo de trabalho aparece como centro do tempo e o tempo livre das férias, do desemprego, como tempo de uma periferia, subúrbio do tempo" (Virilio, 1995a, p.11), que se pode tomar em comunhão com a expressão tempos mortos adotada por Dal Rosso (1996), que denota igualmente o caráter utilitário do tempo aos olhos do capital.

A obra de Virilio e de Lévy possibilita que se pensem alguns vínculos com a administração e a psicologia social e do trabalho em particular, ao considerar-se a velocidade enquanto nova forma simbólica da cultura (Thompson, 1995). Enigma central da contemporaneidade a acarretar mudanças radicais dos conhecimentos operacionais de uma mesma profissão, a velocidade vem implicar a exigência de reorganização em tempo real também dos agenciamentos cognitivos pessoais, uma vez que a flexibilidade demandada não se restringe apenas aos processos de produção e aos circuitos de distribuição, atingindo, demasiadamente, os sujeitos do trabalho.

Ao objetivar-se nas intercorrências do cotidiano, particularmente expressa no mundo do trabalho, a velocidade aponta novos modos de ser construídos a partir de distintas maneiras de homens e mulheres experimentarem o tempo. Diante de tal incontestabilidade, faz-se notar a importância de se compreender como o ritmo acelerado das mudanças e, conseqüentemente, o ritmo acelerado do trabalho influenciam a subjetividade.

A psicologia tem feito amplo uso do termo subjetividade, nos últimos tempos, e o faz de maneiras diversas, dependendo da inserção e da tradição que caracteriza as práticas psicológicas vigentes. Opta-se pela ótica proposta por Guattari e Deleuze (apud Deleuze e Guattari, 1996; apud Guattari e Rolnik, 1996; apud Guattari, 1997), de onde se depreende que a subjetividade pode ser entendida como diferentes expressões de como, enquanto trabalhadores, somos afetados (Naffah Neto, 1995) por um mundo natural/subjetivo/social que, sem ser hierarquizável, apresenta-se em constante mutação.

Ao tratar a questão da subjetividade, a questão da objetividade do mundo se faz presente. Não porque lhe designe oposição, mas porque subjetividade e objetividade são instâncias contínuas, constituindo uma à outra e necessitando uma da outra. A subjetividade, antes de ser individual, é coletiva, social e histórica, e relaciona-se com o mundo que a gera, tal como ilustra a Fita de Moebius (vide Figura 1) do artista holandês Maurits Cornelius Escher (1998), apresentando continuidades entre o fora e o dentro, numa operação de dobramento, de onde se depreende que a subjetividade se constitui, nem fora, nem dentro, nem no sujeito, 
nem no mundo, mas justamente entre todos estes. Fora e dentro, sujeito e mundo imbricados, como faces de uma mesma moeda, constituem o ponto central do entendimento da subjetividade.

\section{Figura 1: Fita de Moebius}

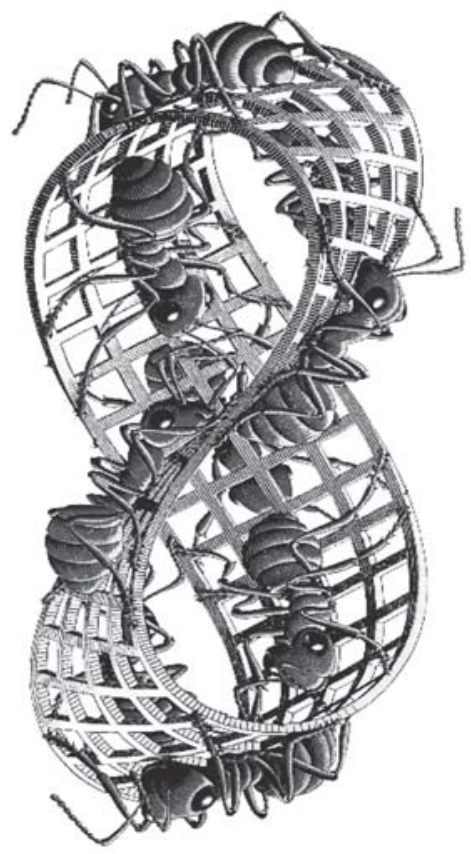

Fonte: Escher (1998).

Essa lógica percorre a discussão de que

"para o indivíduo cujo trabalho é subitamente modificado; para uma dada profissão (tipógrafo, bancário, piloto) bruscamente atingida pela revolução tecnológica, que torna obsoleto o savoir-faire tradicional e ameaça a própria permanência da profissão; para as classes sociais ou para as regiões do mundo que não tomam parte na efervescência de concepção, produção ou apropriação lúdica das novas ferramentas digitais - para todos estes, a revolução técnica manifesta-se como um 'outro' ameaçador. A bem dizer, nenhum de nós deixa de se encontrar mais ou menos nesse estado de despossessão" (Lévy, 1997a, p. 3).

O mundo do trabalho bancário, onde o processo de informatização e os recursos da sociedade da informação se tornam cada vez mais presentes, penetrando 
intensamente nas atividades realizadas pelos bancários e obrigando a reorganização dos postos de trabalho (Harvey, 1993; Chesnais, 1996; Castells, 1999), vem a constituir-se em uma realidade peculiarmente favorável e atraente aos estudos acerca das transformações que deverão gerar novos modos de experimentar o tempo. Ainda mais que, como dizem Guattari e Rolnik (1996, p.323), a “espécie humana está mergulhada num imenso movimento de desterritorialização, no sentido de que seus territórios 'originais' se desfazem ininterruptamente com a divisão social do trabalho", e não mais num movimento arborescente que, tal como as árvores, conserva traços de uma mesma natureza, agindo como "modelo e como decalque transcendentes” (Deleuze e Guattari, 1996, p.31).

Desse modo, a idéia de continuidade ilustrada pela Fita de Moebius (vide Figura 1) indica o propósito de se articular trabalho, tempo e subjetividade enquanto elementos que se conectam por pontos múltiplos. Tal articulação considera duas condições em especial: a realidade do mundo do trabalho como constitutiva do sujeito, bem como a subjetividade vinculada aos processos sociais e históricos.

\section{Procedimentos metodológicos}

\section{O Problema de Pesquisa}

Conforme já referido anteriormente, o problema de pesquisa assim se apresenta:

Como trabalho e tempo, inter-relacionados, repercutem na subjetividade de trabalhadores, especificamente daqueles que exercem as suas atividades no setor de prestação de serviços bancários?

\section{O Método de Pesquisa}

O método adotado para esta pesquisa foi o do estudo de caso. Consagrado pelas comunidades científicas, trata-se de investigação multifacetada, em profundidade, de um único fenômeno social, conduzido em detalhes e baseado em várias fontes de dados (Yin, 1994). O estudo de caso, que não pode ser meramente empírico, devendo relacionar fatos, conceitos e realidade que o contextualizam, traz conhecimento específico de um fenômeno mais amplo (Feagin, Orum e Sjoberg, 1991; Wieviorka, 1995). Como vantagens de realizar-se um estudo de caso, Roesch (1999) aponta algumas características que permitem: fundamentar as observações e conceitos com que se trabalha, por estudar os eventos e as ações humanas de perto, em seu próprio ambiente; estudar o impac- 
to da interação social sobre as decisões dos sujeitos; examinar o fluxo e refluxo da vida social ao longo do tempo e mostrar as mudanças ocorridas nos padrões de vida, no cotidiano, podendo o estudo original vir a ser continuado anos depois.

\section{Os Sujeitos da Pesquisa}

Os sujeitos desta pesquisa foram 38 funcionários pertencentes a diferentes níveis hierárquicos, considerando-se características como sexo, idade, escolaridade, cargo e tempo de trabalho como bancário numa instituição financeira centenária, de grande porte e de abrangência nacional, denominada empresa X, distribuídos em uma proporção igualitária em três agências de grande, médio e pequeno porte, na cidade de Porto Alegre, RS. As três agências que constituíram o local de trabalho dos sujeitos da pesquisa integraram o conjunto de agências em que, à época da coleta de dados, implantava-se um projeto de modernização considerado o ápice da reestruturação produtiva do trabalho bancário na referida instituição.

\section{A Coleta dos Dados}

A coleta dos dados, ocorrida em 1998, baseou-se na investigação de fontes documentais e iconográficas; na realização de dois grupos focais com cinco e oito participantes, respectivamente, que seguiram a orientação proposta por Morgan (1988), que os toma, basicamente, como entrevistas grupais, tendo como ponto central o uso explícito da integração grupal para produzir dados e permitir que os sujeitos se dêem conta de coisas que seriam menos possíveis sem a interação possibilitada em grupo; em 25 entrevistas individuais de estilo semiestruturado, gravadas em fitacassete com a permissão dos entrevistados e, posteriormente, transcritas, realizadas em local e horário de trabalho dos entrevistados com duração aproximada de 60 minutos; além dos dados provenientes do Censo Bancário - Avaliação de Saúde dos Bancários do Rio Grande do Sul (Sindicato dos Bancários de Porto Alegre/ Federação dos Bancários do Rio Grande do Sul, 1997). O banco de dados do referido Censo Bancário contempla mais de 2000 bancários da empresa X em termos de Rio Grande do Sul e mostrou-se útil para a construção da problemática da pesquisa, sinalizando até que os sujeitos da pesquisa se encontram em sintonia com a realidade que vem sendo apontada no setor bancário.

A pesquisa documental foi realizada por meio de consulta a subsídios oferecidos pela empresa: livros que registram sua história; compilações acerca de momentos significativos; material de divulgação de serviços; e folder de divulgação das políticas institucionais. As fontes iconográficas perfazem um total de nove fotografias. Delas, três referem-se a modos antigos de trabalhar e foram cedi- 
das pelo acervo da empresa $\mathrm{X}$, e seis referem-se a modos novos de trabalhar e foram tiradas por uma fotógrafa. Aliadas à memória e ao imaginário dos sujeitos da pesquisa, as fontes documentais e iconográficas permitem que se explore a criação e a passagem do tempo na empresa X.

A fotografia, tomada como tecnologia da inteligência (Lévy, 1996a) e como um modo de subjetivação (Guattari e Rolnik, 1996), à medida que oferece e produz signos a serem interpretados pelo pesquisador na construção da compreensão da realidade social, além de permitir visibilizar e descrever algumas das mudanças ocorridas, possibilitou a construção do próprio texto, deflagrando ao olhar outros significados da problemática estudada. Ao raptar a cena, a imagem fotográfica pode ser tomada como documento. Deste modo, a "figura do tempo na fotografia pode ser expressa por um vértice ou uma linha se cruzando com outra. Esta representação faz-se pertinente à medida que a fotografia pode ser dimensionada como um corte no próprio tempo, uma ruptura temporal” (Mazzochi e Kirst, 2000, p.160).

\section{A Análise dos Dados}

A análise dos dados priorizou o entendimento qualitativo da realidade social, por meio de categorias de cunho coletivo, seguindo orientações de Thompson (1995) para a Metodologia da Hermenêutica de Profundidade, que contribuiu para auxiliar a compreender os substratos mais profundos que embasam o agir administrativo, sendo útil para a descrição dos dados, possibilitando a obtenção da essência dos fatos. Para Thompson (1995) três fases - análise sócio-histórica, análise formal ou discursiva e interpretação/ reinterpretação - constituem a análise do fenômeno em questão. Para tanto, tomou-se como material de análise as transcrições das entrevistas individuais e dos grupos focais, que correspondem a um volume de dados denso e rico, com um total de 430 páginas, a história da empresa $\mathrm{X}$ a partir dos relatos e dos documentos disponibilizados, e as fotografias.

Esse trabalho é de interpretação. "O processo de interpretação é necessariamente arriscado, cheio de conflito e aberto à discussão” (Thompson, 1995, p.376). O próprio Deleuze (1987, p.90) já afirmava: "erramos quando acreditamos na verdade: só há interpretações”. Nesse sentido, ao fazer uma interpretação, "supomos [que ela possa] ser defendida e sustentada de algum modo. [...] Como o fazemos, que tipos de evidência e argumentos empregamos, dependerá de uma variedade de fatores, tais como o campo geral de investigação e as circunstâncias específicas da afirmativa” (Thompson, 1995, p.411). 


\section{Apresentação e Análise dos Dados}

\section{Dos Corpos em Rede às Máquinas em Rede: Historicidade e Modos Organizacionais}

Dados os limites deste artigo, cabe ressaltar a intenção de estabelecer recortes da pesquisa desenvolvida, bem como a idéia de privilegiar a apresentação de alguns dos dados/fatos e ditos coletados, tomando-se a fotografia como elemento deflagrador da compreensão de como algumas das mudanças foram se concretizando no mundo do trabalho bancário, via diferenciações nos modos de trabalhar, nos instrumentos de trabalho, nos modos de experimentar o tempo, entre outros.

A partir das interfaces da história da X, apresentadas e analisadas a seguir, pensa-se ser possível interpretá-la como exemplo de mudanças ocorridas no contexto mundial, uma vez que ela se mostra enquanto concretude de um movimento de globalização da economia, em que a competitividade obriga o próprio Estado a repensar a organização do trabalho. Moldadas pela lógica que rege os interesses do capitalismo, as novas tecnologias adotadas pelo segmento bancário, e pela empresa X em especial, aumentaram a rapidez do fluxo do dinheiro e têm gerado modos de trabalhar diversos, que implicam qualificação, recolocação e também desemprego, conforme registra o Censo Bancário - Avaliação de Saúde dos Bancários do Rio Grande do Sul (Sindicato dos Bancários de Porto Alegre/Federação dos Bancários do Rio Grande do Sul, 1997).

\section{Mudança Arborescente}

A empresa X conta com mais de cem anos no Estado do Rio Grande do Sul, onde, por volta da década de 1940, se inaugurou nova sede da empresa. Do edifício solenemente inaugurado dizia-se ser um dos mais completos da cidade, estando de acordo com as modernas exigências da higiene e bem-estar pessoal, com dependências amplas e ventiladas a oferecerem o máximo de conforto àqueles que lá trabalhavam.

Interessante detalhe acerca do novo edifício leva a pensar acerca da condição que se liga ao caráter das mudanças então emergentes na empresa. O que se toma como detalhe encontra-se ilustrado, de modo significativo, na condição de que o novo edifício conservou as mesmas características nas fundações e subsolo do prédio anterior, incluindo o cofre forte. É essa característica de conservação, de manutenção das raízes e de mudanças apenas nos galhos, própria das árvores, que se identifica como mudança arborescente. 
Conforme Deleuze e Guattari (1996), ao tomarem a árvore enquanto objeto de reprodução externa como árvore-imagem e enquanto objeto de reprodução interna como estrutura-árvore, pensa-se ser possível visibilizar, no detalhe da construção da nova sede, que passa quase que despercebido na história da $\mathrm{X}$, que a mudança que se anunciou à época da construção do novo prédio era de ordem arborescente. Tal mudança, independentemente da época, é tomada pelos sujeitos como mudança que nunca acontece, que se esfuma nos discursos; ou então que propicia certos períodos de adaptação, ao se delinear como algo longínquo e que, ao se avizinhar, ainda possibilita fazeres paralelos, mudança que conserva as características de estrutura, que remete a traços de mesma natureza.

Vislumbra-se, então, uma empresa-imagem e uma estrutura-empresa, ambas a reproduzirem-se nos noticiários da época, ambas a garantirem a reconversão de um modo de trabalhar e de sujeitos do trabalho ainda não desterritorializados de todo, em que pese a força dos discursos que anunciam novos tempos.

\section{Quando se Gestam Mudanças Desterritorializantes}

Na década de 1970, ocorreu a implosão do edifício-sede da empresa X, aquele tido como espaço privilegiado de trabalho na sua inauguração. A respeito do que se poderia chamar de uma tal implosão/reestruturação, toma-se como pertinente pensar os sujeitos de então envolvidos em movimentos de desterritorialização ou de desorientação que os arranca de modos de trabalhar, experimentar o tempo e viver que lhes são familiares.

Tal implosão não mais permite deter-se tão somente à noção arborescente como na construção desse edifício alicerçado em outro, há mais de três décadas, ainda que o cofre forte tenha permanecido intacto. Não obstante a dificuldade de ruptura das amarras que, secretamente, sustentam a empresa-imagem e a estrutura-empresa, enunciado que se lê no cofre que não explodiu, um movimento em prol de mudanças começou a gestar-se, mesmo que ainda não se fizesse notar nitidamente configurado. Essa configuração somente se concretizou, quando à mudança do/no espaço se acoplaram efetivas mudanças do/no tempo que, em se tratando da empresa $\mathrm{X}$, teve seu ápice na implantação de um projeto de modernização, no final dos anos 90.

Mudanças desterritorializantes, desde os efeitos que produzem, são compreendidas pelos sujeitos como metidas à força, regidas por modos de apresentação como inevitabilidade, instantaneidade e intensidade. Mudanças que provocam desassossego e atingem aqueles sujeitos ditos dos postos de gestão, tanto quanto 
aqueles dos postos de execução. Não mais tomadas como "sinônimo de longo prazo" (gerente de área), inscrevem-se no tempo da velocidade, arrancando os sujeitos de territórios solidificados "de uma hora para outra” (caixa executiva).

\section{A Contemporaneidade do Projeto de Modernização}

Da década de 40 à de 90 , mudanças estruturais significativas se fizeram notar na empresa X. Entre elas, reformas para acompanhar a modernização de outros setores do País, unificação das diversas empresas autônomas sob a forma de empresa pública, disputa de mercado com outros bancos, declaração de momento de crise que proclamava por um tempo de esforços e sacrifícios dos sujeitos bancários, e implementação de diversos programas de racionalização e de competitividade. Mudanças essas que apontavam novos modos de trabalhar e de ser sujeito bancário.

Atualmente, a empresa insere-se em contexto em que produtividade, flexibilidade e competitividade são palavras de ordem, e adota a noção de um tempo sem tempo, antimemória. Cria um projeto de modernização único/homogêneo compatível com a racionalidade histórica, objetivando lucratividade via produtividade ordenada. Em geral, os chamados novos modelos de gestão adotados coadunamse aos novos processos e às novas tecnologias que exigem melhor qualificação de cada profissional. Desse modo, o comportamento esperado por parte de seus funcionários pode ser resumido em agilidade nas decisões, disposição para aprender, proatividade e assertividade, flexibilidade e adaptabilidade, postura empreendedora e coerente com a missão da empresa, e co-responsabilidade por resultados empresariais.

Foi no final do século XX que se materializou a idéia do urgentemente na empresa. Isso se deu por meio do projeto de modernização, que visava a prover a empresa dos recursos necessários para funcionar e atender satisfatoriamente aos segmentos de sua atuação, em atenção máxima à realização dos desejos, necessidades e expectativas dos clientes.

O estímulo visual que caracteriza tal projeto diferencia nitidamente o antes e o depois de sua implantação como um todo. A sensação de adentrar-se outro espaço, em detrimento dos mesmos limites impostos pelo prédio, é reforçada pelas modificações em termos de lay-out dos móveis, das cores padronizadas e combinadas, das máquinas, das áreas de circulação ampliadas, que sugerem uma idéia de assepsia. Trata-se de disposição arquitetônica que diferencia o antigo e o novo, a apontar estratégias de suporte à implementação de mudanças e dispositivos de anunciação, como ilustram as Fotografias 1 e 2. 


\section{Fotografia 1: Por Volta da Década de 40: Corpos em Rede Edifício-Sede da Empresa}

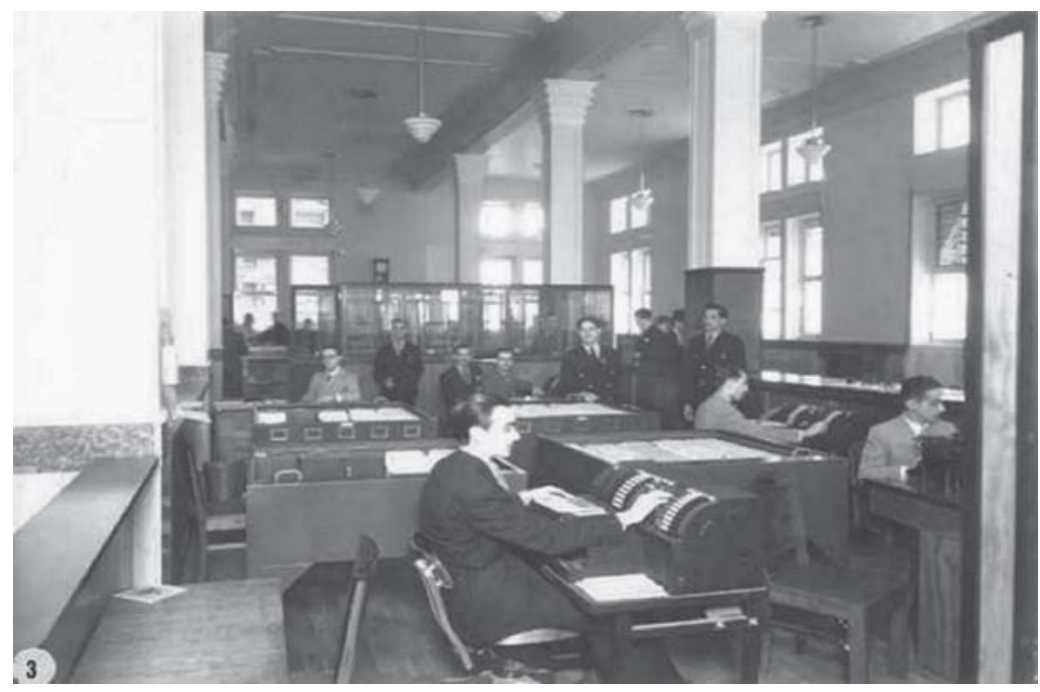

Fonte: acervo da empresa X.

Fotografia 2: Por Volta de 50 Anos Depois: Máquinas em Rede Visão Interna de Agência/1998

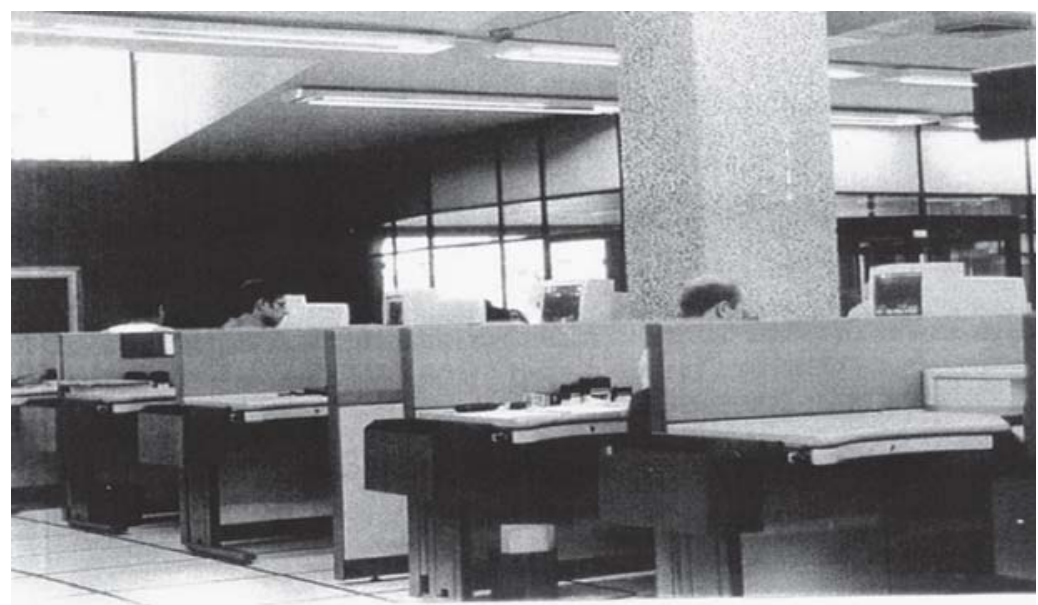

Fonte: fotografia de Patrícia Kirst. 


\section{Dos Corpos em Rede às Máquinas em Rede}

Na Fotografia 2, a nova forma arquitetônica, advinda do projeto, contém o enunciado da experimentação do tempo, insinuando a velocidade a ser imprimida: linhas retas e previsíveis desenham corredores que adquirem status de vias de rápido acesso; a ausência de detalhes e as cores monocromáticas - tons de azul e de cinza - não prendem o olhar, facilitando o passo largo; os movimentos físicos restritos aos lugares individualizados supõem tudo encontrar-se ao alcance das mãos; os corpos enclausurados separadamente permanecem inertes no mesmo lugar, enquanto as informações circulam em redes invisíveis, uma vez que "a rigor, uma pessoa não precisa nem usar telefone, é para usar o sistema” (gerente geral); a temperatura artificial faz presumir a existência de uma única estação do ano, temperatura esta condizente com as exigências de produtividade; a iluminação artificial colore os móveis de modo indiscriminado.

A aparência de um bloco monolítico, monotonamente cinzento a produzir invisibilidade, inércia e isolamento, contrasta com a sinuosidade dos caminhos a serem vagarosamente percorridos entre mesas, cadeiras e divisórias de madeira por natureza multicolorida, dispersas conforme possíveis conveniências, como luminosidade e frescor, oferecidos por generosas janelas, conforme se nota na Fotografia 1. Os corpos em rede salientam-se nesse cenário que remete ao antigo, evocando um tempo por eles ainda ritmado sob o constante vaivém do pêndulo de carrilhão pendurado à parede. De uma arquitetura que ainda permitia a aparência dos corpos, depara-se, hoje, com a arquitetura da homogeneização, da clausura e da separação dos corpos em meio aberto que mantém os sujeitos afundados na estrutura do prédio e privilegia as máquinas em rede.

\section{Da Rede Física à Rede Virtual: o Projeto de Modernização}

Da disposição arquitetônica e das máquinas, entre outros, extraem-se novos enunciados. Enunciados que falam de uma empresa que deixa de ser disciplinar para tornar-se de controle. À empresa disciplinar correspondem as máquinas fixas, não interligadas em rede; à de controle, as máquinas cibernéticas e os computadores, tal qual ilustram as Fotografias 1 e 2. Há, entretanto, de se relembrar o alerta que fazem Lévy (1996b) e principalmente Deleuze (1998, p.216), ao dizer este que "as máquinas não explicam nada; é preciso analisar os agenciamentos coletivos dos quais elas são apenas uma parte. Face às formas próximas de um controle incessante em meio aberto, é possível que os confinamentos mais duros nos pareçam pertencer a um passado delicioso e benevolente”.

"Fidelizar/fidelização” (gerente geral) é palavra que se compõe nesses con- 
troles que são certa modulação. Ela é uma das palavras indicadoras desses novos tempos e, igualmente, uma palavra indicadora de que o vocabulário não dá mais conta das muitas e aceleradas mudanças que ocorrem. Embora não encontrada no dicionário, tem sido utilizada no seguinte sentido: não basta ser cliente, é necessário ser fiel à empresa.

Elaborado a partir de contexto em que as instituições financeiras investem fortemente em tecnologia, buscando "fidelizar" (gerente de área) seus clientes, reduzir custos e aumentar as receitas, o projeto visa a ir além, propondo soluções totalmente novas. Para tanto, apóia-se basicamente na padronização, na automação bancária que visa a redirecionar o cliente da rede física para a rede virtual, em um foco de atenção combinado entre prestação de serviços e negócios, na combinação de tecnologia com racionalização.

O projeto, que prevê fase de transição e fase de implantação total de forma bastante veloz, mostra-se paradigmático das transformações que sofre o mundo do trabalho. Diz muito a respeito dos modos de trabalhar e dos modos de produção de estilos de vida, uma vez que implica reelaboração das formas de relacionamento: dos sujeitos com o próprio trabalho; entre si em posições hierárquicas distintas ou não; com os clientes; e dos clientes com as novas tecnologias.

Nas palavras dos próprios sujeitos que devem responder "eu faço, eu faço, eu faço" (secretária), no formato de um atendimento tempestivo, à totalidade das demandas que se apresentam, evidencia-se que, às mudanças no espaço de trabalho e nos modos de trabalhar, acoplaram-se definitivamente as mudanças do tempo. Condizente com essa idéia, soma-se uma série de providências tomadas pela empresa $\mathrm{X}$ como as seguintes: lançamento de informe publicitário, que oferece um serviço que sugere melhor aproveitamento de cada minuto do dia do cliente; abolição de instrumentos de trabalho historicamente legitimados, como máquinas de escrever elétricas - para que duas remanescentes permanecessem em uma agência, contam os sujeitos ditos antigos, que elas tiveram de ser literalmente "escondidas" (escriturário); e abolição do papel. Papel, aliás, segundo os sujeitos dessa mesma agência, "não combina” com os novos modos de trabalhar e é interpretado como "um acinte” (técnica) nestes novos tempos.

\section{Papel: um Acinte nos Novos Modos de Trabalhar}

Os sujeitos autodenominados antigos, de modo mais acirrado do que aqueles autodenominados novos, não compreendem como uma empresa burocrática não queira trabalhar com papel. Há de se ressaltar, no entanto, que a burocracia não se restringe ao uso do papel, configurando-se também, entre outros, nos procedimentos e na impessoalidade que caracterizam os novos modos de trabalhar. 
As Fotografias 3 e 4 ilustram algumas das providências listadas anteriormente e contrastam modos antigos e novos de trabalhar, via instrumentos de trabalho, relacionamento entre colegas e armazenamento da informação, entre outros.

Fotografia 3: Por Volta de 1940: Tempos Modernos. Ilustração de um Modo Antigo de Trabalhar com Papel

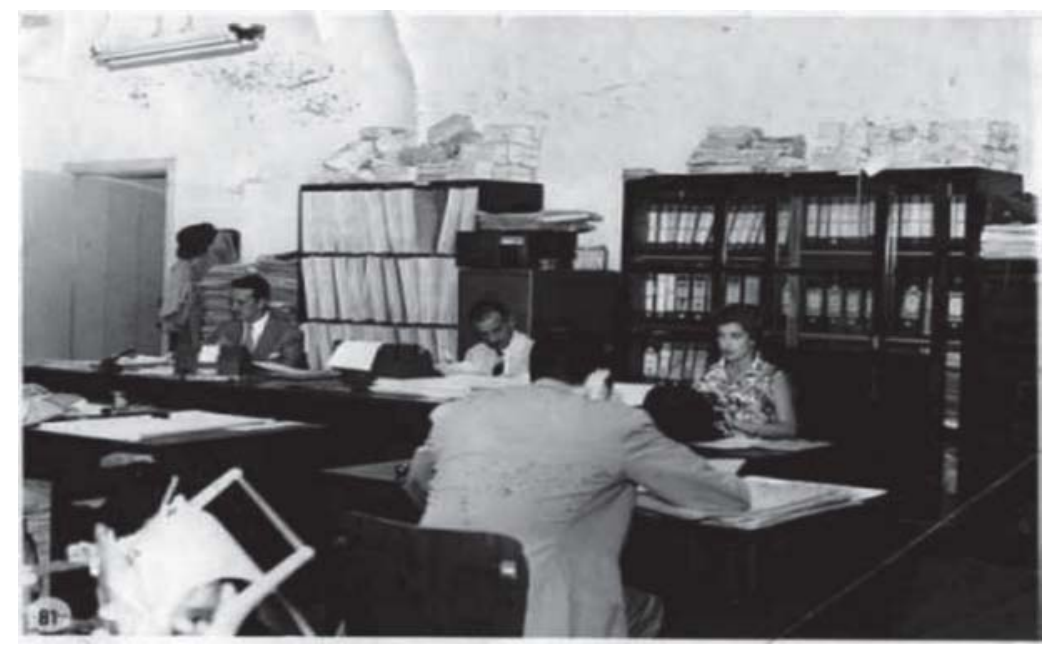

Fonte: acervo da empresa X.

Fotografia 4: Por Volta de 50 Anos Depois: Tempos Mutantes. Fase de Implantação do Projeto

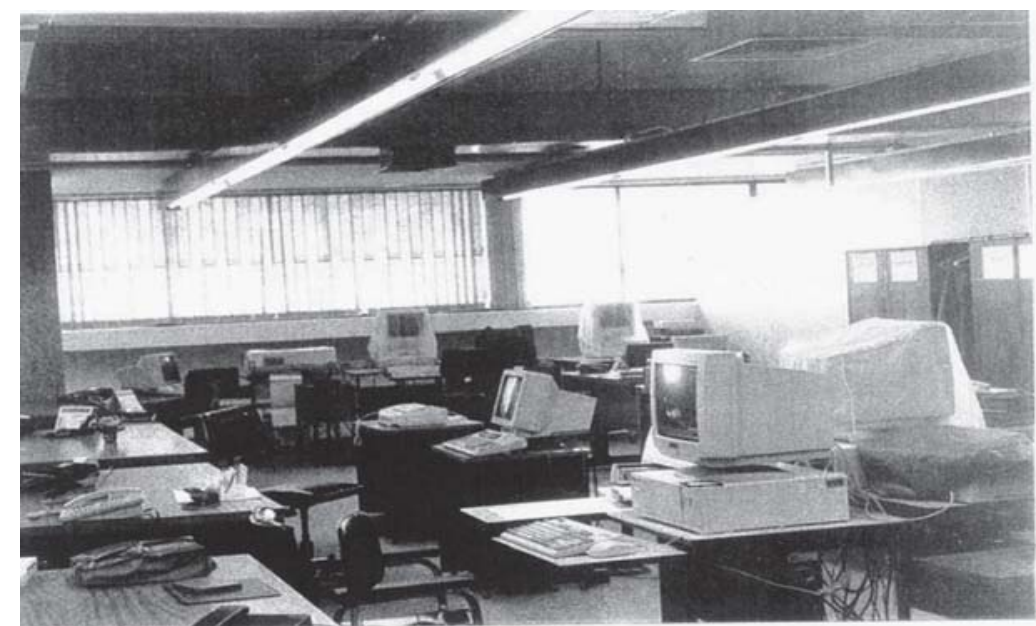

Fonte: fotografia de Patrícia Kirst. 
Além de realçar a idéia de corpos em rede e de máquinas em rede, como nas Fotografias 1 e 2, já vistas, nota-se que as de números 3 e 4 reafirmam a posição de destaque que assumem os computadores e comprovam o desaparecimento do papel em contraste com os moldes antigos. A comparação das Fotografias 3 e 4 implica pensar a memória visível e a memória invisível do trabalho.

Condizente com os modos antigos de trabalhar (vide Fotografia 3), no final de uma jornada, o produto do trabalho realizado pelo sujeito fazia-se notar nas visíveis pilhas de papel a atestar, indiscretamente, a presença da memória estocada. Todos poderiam compartilhar uma possível sensação apaziguadora que, por ventura, a concreta presença das folhas de papel proporcionasse. Característico da sociedade da escrita, o resgate da memória do trabalho poderia desencadear uma busca seqüencial e cumulativa das informações armazenadas por escrito, o que sugeria a experimentação do tempo tomado como linear e histórico.

Há de se considerar, igualmente, que um cenário semelhante ao retratado na Fotografia 3 perdurou por longo tempo e produziria um choque em funcionária com apenas oito anos de empresa, do mesmo modo que produz o cenário que ela conhecera em algum momento de sua trajetória na empresa, quando comparado ao ambiente atual. Isso porque, em sua avaliação, "atualmente tá mais limpo o visual, não tem tanta coisa. Tinham muitos relatórios que não tinham onde ser guardados, e ficava aquilo aparecendo, e aquilo dá uma certa [...] parece casa que não está arrumada. E como agora as coisas têm [...] foi previsto lugar, eu acho que a coisa fica mais limpa, um ambiente mais limpo, mais claro” (escriturária).

Na Fotografia 4, que possibilita visibilizar uma empresa em rede, a presença da memória invisível do trabalho fica por conta da rede de informática, em que há remanejamento e atualização permanente dos dados, que não mais se acumulam sob a idéia de um passado cronológico a ser vasculhado, mas que se configuram como operação não datada, em constante condensação no presente.

Desse modo, no final de uma jornada, o que se faz notar não é mais o produto do trabalho concreto e atualizado pelo sujeito no papel encarado como acinte nos novos modos de trabalhar, mas a experimentação do tempo embaralhado da informática. Enquanto o acúmulo de papel remete à expansão no espaço, a rede de informática remete à implosão do tempo. Já é possível, portanto, de modo mais veemente, tomar-se o tempo como fator preponderante na questão da reestruturação do trabalho bancário. Cabe, portanto, lembrar que se apresenta como necessário romper com a idéia do tempo linear, da sucessão linear, já que se faz notar, nesse momento, não a existência de tempo cíclico, mas uma lógica institucional, que enfoca regimes de temporalidade, em que circulam sentidos que fazem redes com o passado e o próprio futuro. 
Por meio dessa lógica institucional, obtém-se uma visão geral de alguns dos encaminhamentos propostos pela empresa e de como eles podem vir a afetar os modos de trabalhar, instrumentos de trabalho, modos de experimentar o tempo, modos de subjetivar ou de produzir estilos de vida, denotando a dinamicidade que envolve uma empresa de tal porte.

\section{Modos Antigos e Modos Novos de Trabalhar e de Mudar na Empresa X e a Constituição do Sujeito}

Enquanto aspecto central na compreensão do fenômeno estudado, a denominação de antigo e novo referente aos modos de trabalhar se faz notar nas diversas categorias que brotam da análise. Como se verá no quadro a seguir, elaborado a partir das falas dos próprios sujeitos da pesquisa, antigo e novo inscrevem-se para além de um sentido meramente cronológico, oferecendo visão panorâmica quanto à maneira do trabalhar bancário, quanto à regimes temporais e à modos de subjetivação ou produção de estilos de vida. Antigo e novo mostram-se relativos a um modo de subjetivar que diz respeito, entre outros sentidos, à resistência às mudanças e à experimentação inusitada da exigência de um novo perfil de bancário pela empresa.

As falas dos sujeitos, no que diz respeito aos modos antigos de trabalhar, apontam, em linhas gerais, a divisão e simplificação de tarefas caracteristicamente tayloristas, a experimentação de tempos lentos, tempos de certezas e de estabilidade e o trabalho compreendido como emprego vitalício. No que diz respeito aos modos novos de trabalhar, apontam, em linhas gerais, a intensificação dos ritmos de trabalho, o que acarreta mudança estrutural e veloz, que torna os sujeitos obsoletos e diz da supersolicitação e do sofrimento psíquico que experimentam.

As mudanças do trabalho, aos olhos do sujeito que as sofre, só comportam uma certeza, a da velocidade de sua implantação. A imprevisibilidade e as incertezas que tal velocidade suscita quanto ao futuro, geram sentimentos de angústia e medo de fracassar. O sujeito bancário se vê, sem trégua, defrontado com o que define como "a perda do fio da meada" (gerente geral), representada na possibilidade de perda da auto-referência, que se dá, entre outros, pela substituição dos instrumentos de trabalho, dos modos de trabalhar e de se relacionar, que outrora lhe conferiam uma dada qualificação e segurança; pela ameaça coercitiva do desemprego e pela ameaça da própria extinção enquanto profissão. 


\section{Quadro 1: Modos Antigos e Modos Novos de Trabalhar e de Mudar na Empresa $X$}

\begin{tabular}{|c|c|}
\hline Modos antigos de trabalhar & Modos novos de trabalhar \\
\hline $\begin{array}{l}\text { Ritmo do trabalho e ritmo da vida mais lentos: } \\
\text { "Não era muito cabeça quente. Chegavas, atendias, } \\
\text { fazias, chegavas ao final do dia, mandavas o teu } \\
\text { malotezinho e acabou" (caixa executiva). } \\
\text { "Antes era uma coisa mais calma. Tu administravas } \\
\text { melhor o teu trabalho, tu tinhas tempo de respirar, } \\
\text { tempo de tomar um copo de água, de tomar um } \\
\text { cafezinho. Antes era um tempo no tempo, agora é um } \\
\text { tempo atropelado" (escriturário). }\end{array}$ & $\begin{array}{l}\text { Ritmo do trabalho e ritmo da vida acelerados: } \\
\text { Fica todo mundo querendo resolver as coisas para } \\
\text { ontem [...] é um estresse violento. A gente pensa, às } \\
\text { vezes, tenta sair um pouco fora. No serviço é uma } \\
\text { correria, tu tens um ritmo, não consegue sair, não } \\
\text { consegues chegar e dizer: 'Eu sou diferente'. Tu estás } \\
\text { fora do teu grupo, os outros mesmos te excluem, te } \\
\text { tiram. É um ligar, os outros têm que ir, todo mundo, } \\
\text { não é tu que faz, não é um que diz; as coisas ficam } \\
\text { mais rápidas, até em termos de resposta de trabalho, } \\
\text { quanto mais rápido tu fizeres as coisas, mais rápido tu } \\
{[\ldots] \text { tem outras tarefas" (escriturário). }}\end{array}$ \\
\hline $\begin{array}{l}\text { Tempo das certezas: } \\
\text { "Tinha gente que tinha a empresa como um fim: eu vou } \\
\text { crescer dentro da empresa, vou me aposentar nela, ela é } \\
\text { uma maravilha" (escriturário). } \\
\text { "O ingresso na X representava "um troço para o resto } \\
\text { da vida naquele tempo. E era mesmo, naquele tempo } \\
\text { era" (escriturário). }\end{array}$ & $\begin{array}{l}\text { Tempo das incertezas: } \\
\text { "Essa questão do-que-eu-fiz morreu. O que as pessoas } \\
\text { fizeram no passado não tem mais valor nenhum no } \\
\text { presente. [...] as transformações atropelaram ela } \\
\text { [pessoa]; passaram por cima. É muita velocidade" } \\
\text { (gerente geral). } \\
\text { "Da uma insegurança de que daqui uns dias não } \\
\text { precisam mais de ti. Tá, é legal, é bonito de ver, mas } \\
\text { daí bate um medo assim: 'Até quando eu vou ser útil?" } \\
\text { Chega a dar depressão de pensar que daqui uns tempos } \\
\text { [...] Dá um pânico! Esse medo de como é que vai ser o } \\
\text { teu futuro, o futuro dos teus filhos" (escriturária). }\end{array}$ \\
\hline $\begin{array}{l}\text { Constituição do sujeito bancário: } \\
\text { "Não que antes a gente fosse irresponsável, mas tu não } \\
\text { precisavas te preocupar tanto. Por trás nós tínhamos um } \\
\text { pessoal que resolvia esse problema" (escriturária). } \\
\text { "Aqueles funcionários acomodados, carimbando } \\
\text { papelada, aquela coisa muito lenta, muito se } \\
\text { arrastando" (gerente de área). }\end{array}$ & $\begin{array}{l}\text { Constituição do sujeito bancário: } \\
\text { "A coisa é tão automática. Tu mesma ficas } \\
\text { impressionada. Eu fico meio assustada, sabe. A coisa } \\
\text { vai muito no automático. Ontem eu brinquei que vou } \\
\text { ficar louca. Mas tem horas que parece que tu vais, } \\
\text { realmente. Parece que a cabeça esvazia" (escriturária). } \\
\text { "Sempre correndo atrás da máquina, sempre, sempre } \\
\text { acelerando, sempre estressado. É um pique violento" } \\
\text { (escriturária). } \\
\text { "Ninguém abre o jogo assim, com medo de alguma } \\
\text { coisa" (gerente geral). } \\
\text { "Cada vez a pessoa vai valer menos, se qualificar mais } \\
\text { e ser pior remunerada" (assistente de gerência). } \\
\text { "Na minha opinião a empresa tem que mudar muito } \\
\text { mais ainda. Aliás, é uma questão de sobrevivência. Há } \\
\text { dias em que se fica mais de onze horas aqui dentro, em } \\
\text { reuniões. Enclausurado aqui dentro! Mas é o que a } \\
\text { gente tem que fazer" (gerente geral). }\end{array}$ \\
\hline
\end{tabular}

Fonte: dados da pesquisa.

Cabe ressaltar que, para os sujeitos ditos da gestão, os modos de anunciação das mudanças se expressam por meio de artifícios como reuniões, encontros e seminários, operadores de um tempo que se pode denominar de tempo de transição, que possibilita o engendramento de mecanismos de adaptação às mudanças, já que as antecedem. Para o sujeitos ditos da execução, os modos de anunciação das mudanças dão-se concomitantemente com a sua implantação, com a chegada de equipamentos e móveis novos e modificação de lay-out, por exemplo. A lógica de anunciação 
que permite a alguns se adaptarem às mudanças, com o objetivo de implantá-las, e impõe-nas a outros, abruptamente, caracteriza-se, como já referido anteriormente, por três aspectos básicos: inevitabilidade, instantaneidade e intensidade.

\section{Considerações Finais}

A reestruturação do trabalho bancário tem levado à caracterização de um sujeito supersolicitado, em constante desterritorialização, que se vê sem passado e sem futuro. Sua caracterização passa pelo atravessamento de uma velocidade e sofrimento psíquico que deixam marcas indeléveis. Os modos novos de trabalhar mostram-se coerentes com a acumulação flexível e a compreensão de uma experimentação diferenciada do tempo, que aponta a pressão e o medo em ritmo de trabalho e de vida acelerados. Quanto mais a reestruturação se configura, mais os sujeitos compartilham a idéia de que o futuro da empresa não precisa deles e mais postergam um modo supostamente próprio de experimentar o tempo, arraigando um dever psíquico de submissão à servidão, já que consideram que o tempo não é mais seu, que eles não têm mais direito de ter tempo, uma vez que quem faz o seu tempo é a empresa.

A empresa constitui-se, no exato momento da implantação da mudança, ao mesmo tempo produto e produtora do fenômeno da reestruturação do trabalho. Exemplar no que diz respeito a uma sociedade de controle, substitui antigas formas de disciplina que, agora, se mostram mais sutis. Apresenta um tempo fabricado sob a ordem da velocidade inimaginável, diferentemente daquele sob a ordem da cadência e da periodização que caracterizava a Revolução Industrial, considerada marco inaugural da velocidade. Busca vender tempo, em prol de uma dita qualidade de vida, construída como demanda de uma coletividade que também habita a velocidade.

Em face da reestruturação do trabalho bancário, diferentemente da era da industrialização, os modos de trabalhar demandados caracterizam-se como flexíveis e complexos. Modos de trabalhar que, cabe ressaltar, remetem à experimentação da instantaneidade, de um tempo sem tempo. Trabalho e tempo, assim caracterizados, continuam constituindo-se, sob a chancela do capital, em modos de produção de subjetividade deliberadamente impostos pela empresa aos sujeitos em processo que não tem fim, uma vez que o tempo nunca cessa de causar mudanças na vida institucional. 
RefERÊnCIAS Biblográficas

CASTELLS, M.

A sociedade em rede. São Paulo: Paz e Terra, 1999. v. 1.

CHANLAT, J. F.

Modos de gestão, saúde e segurança no trabalho. In: DAVEL, E.; VASCONCELOS, J. (Orgs.). 'Recursos' humanos e subjetividade. Petrópolis: Vozes, 1996.

CHESNAIS, F.

A mundialização do capital. Rio de Janeiro: Xamã, 1996.

DAL ROSSO, S.

A jornada de trabalho na sociedade: o castigo de Prometeu. São Paulo: LTR, 1996.

DELEUZE, G.

Proust e os signos. Rio de Janeiro: Forense Universitária, 1987.

Conversações: 1972-1990. Rio de Janeiro: Editora 34, 1998.

ESCHER, M. C.

Moebius strip II. Disponível em: <http://www > Acesso em: 19 maio 1998.

FORRESTER, V.

O horror econômico. São Paulo: UNESP, 1997.
GUATTARI, F.

Caosmose: um novo paradigma estético. Rio de Janeiro: Editora 34, 1997.

GUATTARI, F.;

ROLNIK, S.

Micropolítica: cartografias do desejo. Petrópolis: Vozes, 1996.

HARVEY, D.

Condição pós-moderna: uma pesquisa sobre as origens da mudança social. 2. ed. São Paulo: Edições Loyola, 1993.

ITANI, A.

Subterrâneos do trabalho: imaginário tecnológico no cotidiano. São Paulo: Hucitec, 1997.

\section{LÉVY, P.}

As novas tecnologias da inteligência: o futuro do pensamento na era da informática. Rio de Janeiro: Editora 34, 1996a.

O que é o virtual? Petrópolis: Vozes, 1996b.

O digital e a inteligência coletiva. Folha de S. Paulo, 06 jul. 1997. Caderno Mais, p. 3.

MATTOSO, J.

A desordem do trabalho. São Paulo: Scritta, 1995. 
MAZZOCHI, N.;

KIRST, P.

A fotografia como tecnologia da inteligência. In: PELLANDA, N.; PELLANDA, E. (Orgs.). Ciberespaço: um hipertexto com Pierre Lévy. Porto Alegre: Artes e Ofícios, 2000.

\section{MORGAN, D.}

Focus groups as qualitative research. London: Sage Publications, 1988.

NAFFAH NETO, A.

A subjetividade enquanto éthos. Cadernos de Subjetividade, v. 3, n. 2, p. 197-200, set.-fev. 1995.

ROESCH, S.

Projetos de estágio e de pesquisa em administração: guia para estágios, trabalhos de conclusão, dissertações e estudos de caso. 2. ed., São Paulo: Atlas, 1999.

ROLNIK, S.

Cartografia sentimental: transformações contemporâneas do desejo. São Paulo: Estação Liberdade, 1989.
SINDICATO DOS BANCÁRIOS DE PORTO ALEGRE.

Federação dos Bancários do Rio Grande do Sul. Coletivo Estadual de Saúde. Censo de saúde dos bancários do Rio Grande do Sul. Porto Alegre, 1997.

THOMPSON, J. B.

Ideologia e cultura moderna: teoria social crítica na era dos meios de comunicação de massa. Petrópolis: Vozes, 1995.

VIRILIO, P.

O espaço crítico e as perspectivas do tempo real. Rio de Janeiro: Editora 34, 1995.

A arte do motor. São Paulo: Estação Liberdade, 1996a.

Velocidade e política. São Paulo: Estação Liberdade, 1996b.

YIN, R.

Case study research: design and methods. 2. ed. London: Sage Publications, 1994. 